\title{
ADJUNCTS AND THE INTERNAL STRUCTURE OF VP*
}

\author{
Ken-ICHI TAKAMI \\ Shizuoka University
}

\begin{abstract}
This paper attempts to make clear that there are two distinct types of adjuncts, which we call central and peripheral adjuncts. This proposal leads us to claim that there are three distinct levels of verb phrases, with one level for (adverbial) complements being added, and we call these three levels $\mathrm{V}^{1}$, $\mathrm{V}^{2}$, and $\mathrm{V}^{3}$.

Furthermore, we point out that the two-level hypothesis for VP generally assumed in the recent framework of X-bar theory fails to capture in a consistent and convincing manner the differences which we observe in this paper.
\end{abstract}

0. Introduction. It is generally assumed in the recent framework of X-bar theory (e.g. Jackendoff 1977, Nakajima 1982, Chomsky 1981a, b, 1982, 1986a, 1986b, Emonds 1985) that verb phrases fall into two distinct types or levels: the one level consisting of the head and its complement(s) $(\overline{\mathrm{V}})$, and the other a higher projection consisting of $\overline{\mathrm{V}}$ and any optional adjunct(s)/modifier(s) and specifier(s) (VP, $\overline{\bar{V}}$ or $\left.V^{2}\right) .^{1}$ Observe, for example, the following sentences.

(1) a. John put a bird in the blue cage.

b. Jack treated Mary impolitely.

(2) a. John smoked a cigar in Regent's Park.

b. Jack visits New York frequently.

* I wish to express my gratitude to Bruce D. Davison, who was so generous with his native speaker's intuition, read an earlier draft and provided me with a lot of insightful comments and suggestions. My thanks are also due to Sadao Takatsuki, Heizo Nakajima, Harumi Sawada, and two anonymous EL reviewers, from whose comments I have greatly benefited.

${ }^{1}$ It should be noted, in passing, that Jackendoff 1977, Nakajima 1982 and Emonds 1985 consider $\mathrm{S}$ as a projection of $\mathrm{V}$, and hence $\mathrm{V}$ projects up to $\mathrm{V}^{3}(=\mathrm{S})$. In the GBframework proposed in the recent works by Chomsky, in contrast, $S$ is considered as a

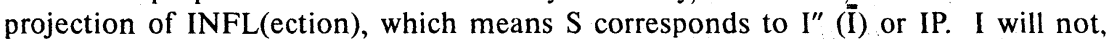
however, go into the problem of whether $\mathrm{S}$ is a projection of $\mathrm{V}$ or of INFL, since this is not directly relevant to the present discussion. 
Since the adverbials in la, b subcategorize the verbs (hence called adverbial complements), they are assumed to occur under $\overline{\mathrm{V}}$. The adverbials in $2 \mathrm{a}, \mathrm{b}$, in contrast, do not subcategorize the verbs and they are called adjuncts. Hence they are assumed to be dominated under VP, the node one level higher than $\overline{\mathrm{V}}$.

It is important to note here that there is another difference between those elements dominated under $\overline{\mathrm{V}}$ and those under VP. The pro-form do so includes the former as its part, but not the latter, as exemplified in $3 \mathrm{a}, \mathrm{b}$.

(3) a. *Jack treated Mary impolitely, but Harry did so politely.

b. Jack visits New York frequently, but Harry does so occasionally.

The pro-form did so in the second clause of 3a is interpreted to substitute for treated Mary impolitely, which contradicts the adverb politely. On the other hand, the pro-form in 3b substitutes only for visits New York, and hence no contradiction results (see, for instance, Jackendoff (1977: 58) and Nakajima (1982: 360)). ${ }^{2}$

In this paper we propose to distinguish between two levels for adjuncts on the basis of X-bar theory, which means that we must set up three distinct levels of verb phrases, with one level for complements being added. Furthermore, we would like to point out that a two-level X-bar theory mentioned above briefly cannot capture the differences in syntactic (and semantic) phenomena we will see below, or that it must, in the attempt, have recourse to a number of unsatisfactory stipulations, which in contrast can be avoided under our proposal.

1. Central and peripheral adjuncts. Let us first exemplify the two types of adjuncts we would like to distinguish. Observe the following pairs of sentences, where we will call the adjuncts in the a-alternatives "central" and those in the b-alternatives "peripheral".

${ }^{2}$ Notice in relation to $3 \mathrm{~b}$, however, that when an element under VP in the first clause is not in contrast with one in the second clause, the pro-form do so may also substitute for that element in the first clause, as seen in (i).

(i ) Jack visits New York frequently, and Harry does so, too. (=visits New York frequently)

3 I owe the terms central and peripheral to Quirk et al. (1985: 511-4). They use the term optional predication adjunct for adjuncts which do not subcategorize verbs but which are more closely connected with the verbs than adjuncts like those in the balternatives in 4-9. For the latter adjuncts they use the term sentence adjuncts. 
(4) a. The gang opened the safe with a drill.

b. The gang opened the safe after sunset.

(5) a. John went to Hawaii with Mary.

b. John went to Hawaii during the vacation.

(6) a. Mary was proposed to by a handsome millionaire.

b. Mary was proposed to in Regent's Park.

(7) a. John drove the car carefully.

b. John drove the car in the main street.

(8) a. They ran three miles in ten minutes.

b. They ran three miles at ten o'clock.

(9) a. Harry hit Mary on the head. ${ }^{4}$

b. Harry hit Mary on the stage.

Adjuncts of means, accompaniment, instrument, agent, manner, etc. will roughly be classified as central adjuncts, whereas those of time and of place will be labeled peripheral adjuncts. But this does not necessarily mean that this classification is always effective; regardless of the fact that both in ten minutes in $8 \mathrm{a}$ and at ten o'clock in $8 \mathrm{~b}$ are adjuncts of time, the former is classified as central and the latter as peripheral. Likewise, on the head in $9 \mathrm{a}$ is classified as central and on the stage in $9 \mathrm{~b}$ as peripheral, though they are both adjuncts of place. A more significant difference between central and peripheral adjuncts develops from how tightly an adjunct is connected with the verb or verb phrase; in $4 \mathrm{a}$, for example, the adjunct with a drill is tightly linked with, and is totally dependent on, the

However, they are not concerned with the structure of these two types of adjuncts, which will be the main purpose of this paper. Dresher 1974 did deal with the structure of prepositional phrases (not from the standpoint of X-bar syntax but from that of phrase structure syntax). However, he collapses (subcategorizing) adverbial complements and adjuncts like those in the a-alternatives of 4-9, and considers them as dominated under VP in a uniform fashion. In his framework, moreover, such adjuncts of time and place as seen in the b-alternatives of 4-9 are assumed to be under the domination of the $\mathrm{S}$ node, which is different from recent syntactic analyses such as Jackendoff 1977 and Nakajima 1982 and from the analysis put forward in this paper.

${ }^{4}$ Although the adjunct on the head in 9 a does not subcategorize the verb, it somewhat differs from other central adjuncts or adverbial complements with respect to the do-so test, as shown in (ia-c). I owe this point to an anonymous EL reviewer.

(i ) a. John went to Hawaii with Mary, and Mike did so with Sue. (cf. 5a)

b. ?Harry hit Mary on the head, and Bill did so on the cheek.

c. *John put a watch on the desk, and Mary did so on the sofa. (cf. 3a) Since many native speakers find (ib) definitely better than (ic) but not quite the same as (ia), on the head in (ib) might be regarded as a "semi-central adjunct" or "semicomplement". 
verb which it modifies. On the other hand, the adjunct after sunset in $4 \mathrm{~b}$ is in a rather loose construction with the verb (that is, semantically less dependent on the verb than the adjunct in $4 \mathrm{a}$ is). Consequently, it tends to modify the sentence as a whole rather than the verb itself, and this reading is easily obtained when the adjunct is preposed to sentenceinitial position (cf. 2.3.). This difference will hold for other adjuncts in 5-9 as well. (We will present arguments for this difference between greater or lesser independence of the adjuncts from the VP in section 2.)

Some further examples in which adverbial clauses are used will be given in 10 and 11, where the adverbial clauses in the a-alternatives are called central adjuncts and those in the b-alternatives peripheral adjuncts.

(10) a. Pronounce the word as I do.

b. Pronounce the word when (because) you are requested to.

(11) a. Giovanni frequently talks as if he knows everything about GB-theory.

b. Giovanni frequently talks since (after) coming back from America.

The adjuncts in 10a and 11a express manner and, like the adjuncts in the a-examples of 4-9, are closely related to the matrix verbs, while those in $10 \mathrm{~b}$ and $11 \mathrm{~b}$ express time (and reason), and they are less tightly connected with the matrix verbs.

The structure we would like to propose for the adjuncts in 4-11, together with subcategorizing (adverbial) complements, is roughly represented in 12:

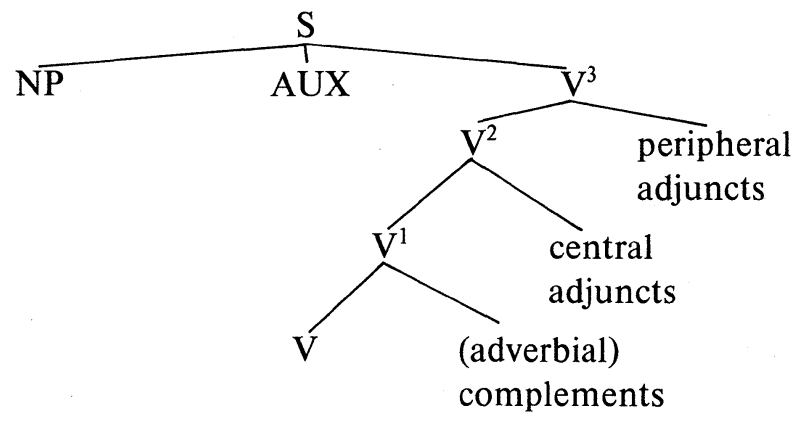

We distinguish three levels of verb phrases, which we call $\mathrm{V}^{1}, \mathrm{~V}^{2}$, and $\mathrm{V}^{3}$. This notation is, of course, that of the so-called X-bar convention; in keeping with that convention, we will assume that $\mathrm{V}^{0}$ is the lexical category V. It is important to notice here not only that the nodes central and peripheral adjuncts are attached to are hierarchically different but 
also that the numbers of the bars for those nodes are different; that is, we do not adopt the so-called "stacked VP" structure as shown in 13, which would perhaps be the structure if we follow the two-level X-bar theory assumed in Chomsky 1981a, b, 1982, 1986a, 1986b and others. ${ }^{5}$ As can be seen in $13, \mathrm{~V}$ projects up to a double-bar level, allowing free recursion at that level.

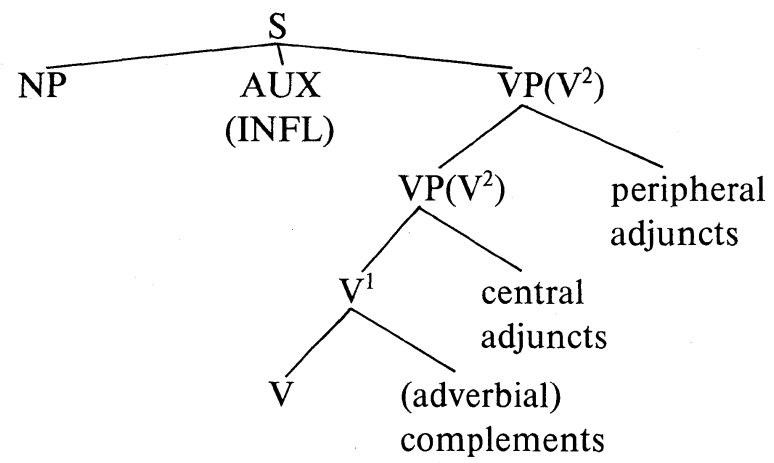

The arguments for rejecting 13 in favor of 12 will be presented directly.

Before going into the syntactic differences between central and peripheral adjuncts, it may be worthwhile noticing here the main reasons why they have so far been treated uniformly as being dominated under

${ }^{5}$ More precisely, 13 could perhaps be represented as in (i) in the framework of Chomsky 1986b.

(i)

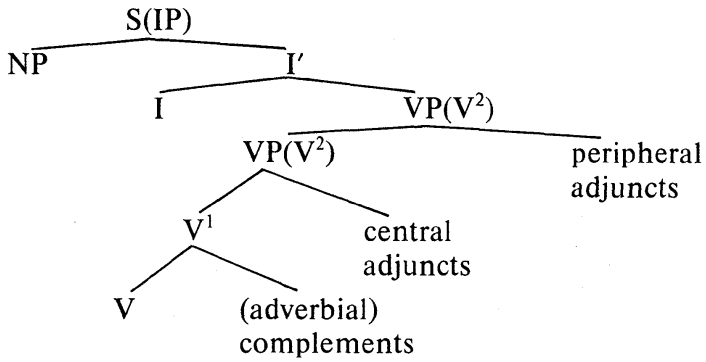

Chomsky 1986b suggests another possibility that adjuncts may be dominated under $\mathrm{S}$ (IP). However, as Hasegawa 1986 and others also point out, this option must be rejected partly because VP-movement can be applied to adjuncts as seen in (ii), and partly because of the discussions presented below in the text.

(ii ) a. John tried to kiss Mary on the cheek. and kiss Mary on the cheek he certainly did.

b. John tried to kiss Mary in the woods, and kiss Mary in the woods he certainly did. 
VP $\left(V^{2}\right)$ (see, for example, Jackendoff 1977). First, it is generally assumed (e.g. Greenbaum 1969, Quirk et al. 1972, 1985) that adverbials under $\mathrm{V}^{2}$ can be modified by such "focusing subjuncts" as only, just, simply or even. This applies to both types of the adjuncts in 4-11, as seen in 14 , for example.

(14) Harry hit Mary only $\left\{\begin{array}{l}\text { on the head. } \\ \text { on the stage. }\end{array}\right\}$

Second, and this is to a certain extent related to the first point, it is possible to focus on adverbials under $\mathrm{V}^{2}$, as exemplified below (cf. Kuno 1975, Jackendoff 1977, Nakajima 1982).

(15) a. It is by a handsome millionaire that Mary was proposed to.

b. It is in Regent's Park that Mary was proposed to.

Third, adverbials under $\mathrm{V}^{2}$ can serve as a response to $w h$-questions, and this holds true for both types of adjuncts in question, too.

(16) A: Where did Harry hit Mary?

B: On the head./ On the stage.

Fourth, it is generally believed that the predicate part of a pseudo-cleft construction can contain only $\mathrm{V}^{1}$ - or $\mathrm{V}^{2}$-material (cf. Ross 1973, Reinhart 1976, 1981, 1983). Thus the application of the pseudo-cleft construction to these two types of adjuncts will yield the following grammatical sentences in both cases.

(17) a. What you should do is pronounce the word as I do.

b. What you should do is pronounce the word when you are requested to.

Finally, we will apply the test of VP-deletion, from which we can ascertain whether a certain element is to be regarded as $\mathrm{V}^{2}$-material. Observe the following sentences.

(18) a. Giovanni frequently talks as if he knows everything about GB-theory, but Jack never does. (=talks as if he knows everything about GB-theory)

b. Giovanni frequently talks since coming back from America, but Jack does not. (=frequently talk since coming back from America)

Since in both $18 \mathrm{a}$ and $18 \mathrm{~b}$ the deleted elements in the second clauses are interpreted as including the adjuncts, both types of adjunct can be regarded as belonging to $\mathrm{V}^{2}$.

2. Arguments for Central and peripheral adjuncts

2.1. ORDER. Let us turn now to the differences between central and 
peripheral adjuncts. It is well-known that elements belonging to different layers can co-occur without necessitating the use of and, in the sequence where more "central" elements are put closer to the same head. Now observe the following co-occurrence contrast of adjuncts.

(19) a. The gang opened the safe with a drill after sunset.

b. ??The gang opened the safe after sunset with a drill. ${ }^{6}$

(20) a. Harry hit Mary on the head on the stage.

b. *Harry hit Mary on the stage on the head.

(cf. Quirk et al. 1985: 512)

(21) a. Pronounce the word as I do when you are requested to.

b. *Pronounce the word when you are requested to as I do. Notice also that when central and peripheral adjuncts co-occur, only peripheral adjuncts can be preposed, as seen in the following examples (cf. Quirk et al. (1985: 512)), which will be closely related to the arguments given below in 2.3 .

(22) a. *With Mary John went to Hawaii during the vacation.

b. During the vacation John went to Hawaii with Mary.

a. *As if he knows everything about GB-theory he frequently talks after coming back from America.

b. After coming back from America he frequently talks as if he knows everything about GB-theory.

It follows from examples 19-23 that there are at least two types of adjuncts which belong to different layers and that, as Quirk et al. (1985: 512) observe, a central adjunct is typically located closer to the center of the sentence than a peripheral adjunct is.

Note furthermore that although nuclear stress (accent) normally falls on the rightmost lexical category in a sentence, the a-sentences in 19-21 do not exhibit this nuclear stress pattern, in the sense that the rightmost lexical category of a central adjunct rather than of a peripheral adjunct tends to be given nuclear stress. For instance, 19a is pronounced as "The gang opened the safe with a DRILL after sunset" (cf. Rochemont 1986). This point concerning pronunciation would indicate that central adjuncts may represent more "important" or newer information than peripheral adjuncts (cf. 2.3., 2.4.).

${ }^{6}$ Note that this sentence turns out acceptable if a big pause (a comma in writing) is put after the adjunct after sunset, and with a drill is uttered as additional information such as afterthought. This is the case with $20 \mathrm{~b}$ and $21 \mathrm{~b}$ as well. 
2.2. Pro-forms and their antecedents. It has commonly been held that if a given set of words in a sentence can be replaced by, or serve as the antecedent of, a pro-form, it forms a single constituent. Now observe the following sentences, in which pro-forms and their antecedents are marked with italics.

(24) a. I will run three miles in ten minutes at ten o'clock, and so will John at eleven o'clock.

b. I will run three miles in ten minutes at ten o'clock, and so will John.

These examples show that run three miles in ten minutes as well as run three miles in ten minutes at ten o'clock is a single constituent. Therefore $24 \mathrm{a}, \mathrm{b}$ would constitute evidence for a structure like 12 , where two adjuncts belong to different layers, and against the structure that these two adjuncts are located at an identical layer. ${ }^{7}$

2.3. Preposing. It has sometimes been claimed that subcategorizing elements are unlikely to be preposed, whereas adjuncts can be preposed. This may be due to the fact that complements are tightly connected with the (matrix) verbs and tend to convey new information, which is generally expressed in sentence-final position. On the other hand, since adjuncts are less tightly connected with the (matrix) verbs, they can serve as the theme of the sentence or as given information when they are preposed. Observe the following examples.

7 The co-occurrence restriction discussed in 2.1. and the pro-form/antecedent argument given in 2.2. do not necessarily reject 13 in favor of 12 ; they only indicate that there should be two different layers for adjuncts. This point can further be supported by a number of syntactic tests like the application of the pseudo-cleft construction (cf. $17 a, b)$.
(i )
a. What Harry did was hit Mary on the head on the stage.

b. What Harry did on the stage was hit Mary on the head.

It may be worth recalling here the structure (ii) often referred to as that of an NP like a student of physics with long hair, where the nodes the two PPs are attached to are both $\overline{\mathrm{N}}$, though hierarchically different. Note here that the order of the two PPs cannot be permuted $(* a$ student with long hair of physics). In this connection, see Baker 1978, Hornstein and Lightfoot 1981, Radford 1981 and Fukui 1986, among others.

(ii)

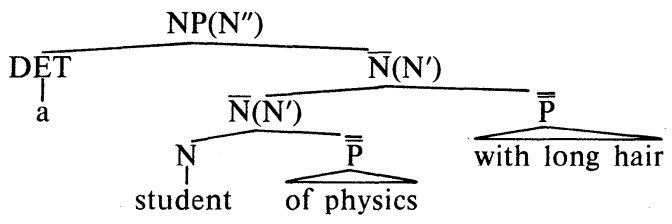


(25) a. *In New York Mike lives.

b. In New York there are a great many skyscrapers.

Note that the grammaticality in $25 \mathrm{a}, \mathrm{b}$ does not change whether a comma (pause) is put after the adjuncts or not. Since this is the case with other examples below (26-32), I will not insert a comma in the examples.

Concerning preposability, however, central and peripheral adjuncts behave differently, as seen in the following examples.

(26) a. ?*With a drill the gang opened the safe.

b. ?* Carefully John drove the car.

c. *As if he knows everything about GB-theory he frequently talks.

(27) a. In 1987 prices will be getting higher and higher.

b. For seven years I have been studying French and Russian.

c. While you are in France you should visit Bordeaux.

This difference would indicate that a central adjunct is, as pointed out above, more tightly connected with the head of the sentence than a peripheral adjunct, and that it never fails to carry new information. ${ }^{8,9}$ We can now say that elements belonging to $\mathrm{V}^{1}$ and $\mathrm{V}^{2}$ cannot be preposed, whereas those belonging to $\mathrm{V}^{3}$ can (cf. 12). It should be noted here that if the sentence had the stacked VP structure like 13, there would be no structural indication of which $\mathrm{V}^{2}$ permits fronting.

2.4. Negation and question. Since central adjuncts are liable to convey new information, they can generally be the focus of negation and of question. Therefore, sentences turn out ungrammatical unless central

${ }^{8}$ The contrast between 26 and 27 will become much clearer, as Quirk et al. (1985: 512) and Dresher 1974 point out, if preposing is combined with a truth-focusing paraphrase.

(i ) a. *With a drill, it is a fact that the gang opened the safe.

b. *It was true that with a drill the gang opened the safe.

(ii) a. After sunset, it is a fact that the gang opened the safe.

b. It was true that after sunset the gang opened the safe.

${ }^{9}$ It is interesting to note here the difference between except (but) and except for (but for). As Close (1975: 178) points out, the former cannot be preposed, but the latter can.

(i ) a. *Except eggs I can eat everything.

b. Except for eggs I can eat everything.

Although we do not go into other details here, it would be safe to say that except $(b u t)+\mathrm{NP}$ is a central adjunct, while except (but) for $+\mathrm{NP}$ is a Disjunct, not a peripheral adjunct. 
adjuncts are located within the scope of negation or of question. Observe the following.

(28) a. * On the head Harry didn't hit Mary.

b. *Toward the park the boys were not running very fast.

c. *As if he knows everything about GB-theory he doesn't frequently talk.

(29) a. *With a drill did the gang open the safe?

b. * Carefully did John drive the car?

c. *As you do should I pronounce the word?

The sentence-initial position in 28 and 29 is outside of the scope of negation and of question, respectively, because their scope extends only over the VP node of each sentence. Hence the ungrammaticality.

In sharp contrast to these central adjuncts, peripheral adjuncts can be located either within the scope of negation and of question or outside of it. Observe the following.

(30) a. For seven years Mary has not seen her old friend Jenny.

b. When John came Mary didn't speak even a single word.

(31) a. Since last month has John visited old temples in Kyoto?

b. Before John came did Mary finish her homework?

The grammaticality in 30 and 31 is attributable to the fact that each of the peripheral adjuncts put sentence-initially expresses given information and hence is the theme of the sentence (cf. setting the scene in Kuno 1975) (cf. 2.3.).

(Adverbial) complements behave in the same way as central adjuncts, as shown in $32 \mathrm{a}, \mathrm{b}$.

(32) a. *In London John doesn't live.

b. *In the drawer did Janet put the letter?

Now we can generalize these phenomena as follows: while elements under (or above) $\mathrm{V}^{3}$ can be put sentence-initially, being excluded from the scope of negation and of question, those under $\mathrm{V}^{1}$ and $\mathrm{V}^{2}$ cannot. Notice here again that if we adopted a structure like 13 , we would have no way of identifying which $\mathrm{V}^{2}$ could be located out of the scope of negation and of question, except by setting up an ad hoc stipulation, which is obviously an unsatisfactory step.

2.5. Preposition stranding. Another difference between central and peripheral adjuncts is observed in the phenomenon of preposition stranding. A preposition can be stranded in the case of central adjuncts, while it cannot be in the case of peripheral adjuncts. See the following 
sentences.

(33) a. What did the gang open the safe [pp with t]?

b. Who was Mary kissed [Pp by t]?

c. Who did Mike travel around the world [PP with $t]$ ?

d. Which cheek did Harry hit Mary [PP on t] last night?

e. How many minutes did they run three miles [Pp in $t$ ?

(cf. Dresher 1974)

(34) a. *Which park was Mary proposed to [ ${ }_{\mathrm{PP}}$ in $t$ ?

B.??Which stage did Harry hit Mary [pp on t]?

c. *Which meal did Bill speak to Sue.[pp after t]?

(Nakajima 1984a: 105)

d. *Which year did Shakespeare finish writing Hamlet $\left[_{\mathrm{PP}}\right.$ in $\mathrm{t}]$ ?

e. *Which vacation did John go to Hawaii [pp during t]?

As with the case of central adjuncts, a preposition can be stranded in the case of adverbial complements, too (cf. Hornstein and Weinberg 1981, Nakajima 1984a, b). Observe the following.

(35) a. Who(m) did you give the present [pp to t]?

(Quirk et al. 1985: 818)

b. What did Janet put her engagement ring [PP on t]?

c. What did Mike talk to Jack [pp about t]?

d. Which city did John live [Pp in t]?

The three cases above may be represented diagrammatically as in 36 . preposition stranding

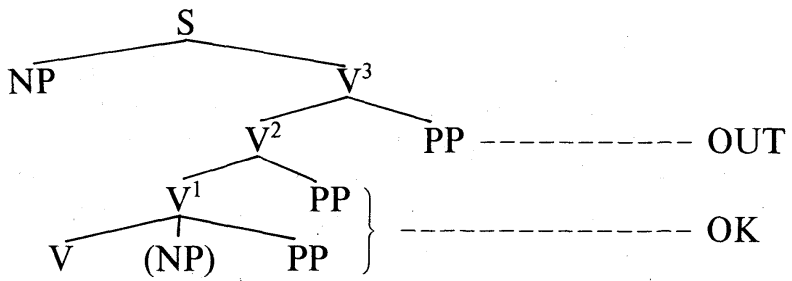

Quirk et al. (1985: 817) state that "the construction with a preposition in final position is less desirable when the preposition is remote from its complement or when it is syntactically bound closer to the complement than to the verb". This may be paraphrased in our framework as follows: a prepositional phrase under $\mathrm{V}^{1}$ or $\mathrm{V}^{2}$ is bound close enough to the verb for the preposition to be stranded, whereas that under (or above) $\mathrm{V}^{3}$ is 
bound so far from the verb that the preposition cannot be stranded..$^{10,11,12}$

We would like to consider here whether the Empty Category Principle (ECP) 37 proposed in Chomsky 1981 can capture the problem of preposition stranding observed above.

${ }^{10}$ Some examples of preposition stranding where prepositional phrases are considered to be dominated under (or above) $\mathrm{S}$ are given below, and they are, as predicted, ungrammatical.

(i ) *What probability will Jack come to the party [pp in t]?

(ii) *Whose opinion will Janet marry that young man $\left[_{P P}\right.$ in t]?

${ }^{11}$ The asymmetry between elements under $\mathrm{V}^{1}$ (and $\mathrm{V}^{2}$ ) and those under $\mathrm{V}^{3}$ might hold for other categories such as an NP and an AP (see Nakajima 1984a, b, among others). Observe the following.

(i ) a. What major do you want to meet $\left[_{\mathrm{NP}}\right.$ a student $\left[{ }_{\mathrm{PP}}\right.$ of $\left.\left.\mathrm{t}\right]\right]$ ?

b. *What hair do you want to meet $\left[_{\mathrm{NP}}\right.$ a student $[\mathrm{PP}$ with $\left.\mathrm{t}]\right]$ ?

(ii) a. What are you $\left[{ }_{\mathrm{AP}}\right.$ certain $[\bar{s}$ that John will do t]]?

b. *What are you $[\mathrm{AP}$ so tired $[\bar{s}$ that you cannot do t]]?

((iia, b) from Nakajima (1984a: 117))

These contrastive examples might partly support the structure (iii) for an NP and (iv) for an AP, which are proposed in Jackendoff 1977, rather than the two-level X-bar structure mentioned in footnote 7 .

(iii)

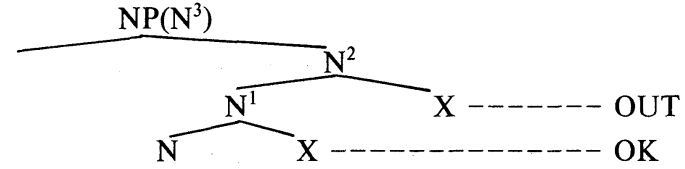

(iv)

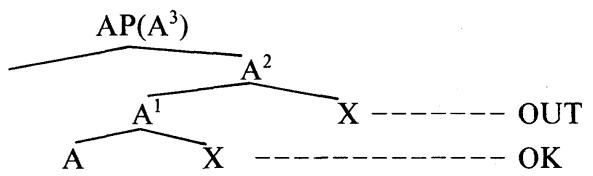

This is because if the sentence had the stacked $\overline{\mathrm{N}}$ or $\overline{\mathrm{A}}$ structure, there would be no indication of which $\overline{\mathrm{N}}$ or $\overline{\mathrm{A}}$ could permit preposition stranding. However, it is not yet immediately clear which structure is more reasonable, because the framework proposed in Chomsky 1981 or Chomsky 1986b (see the text below), which assumes a twolevel X-bar theory, can cope with the phenomenon of preposition stranding as far as (ia, b) and (iia, b) are concerned.

${ }_{12}$ Although the adjuncts of time and place generally disallow preposition stranding, as observed in this paper, it is worth noticing that we can find some counterexamples as in (i).

(i) a. Which book did you find that quote [pp in t]?

(Riemsdijk and Williams 1986: 67)

b. Which state did they build the highway [Pp in t]? (cf. Horn 1974: 40)

c. Which party did John die [pp after t]?

d. the ceremony which you arrive [pp during t] (Larson 1985: 615) ((id) was pointed out to me by an anonymous EL reviewer.)

These examples may suggest that not only syntactic but also semantic (and pragmatic) factors are involved in preposition stranding, but we leave this point for future study. 
(37) ECP: ${ }_{\alpha}$ e] must be properly governed. (Chomsky 1981: 250) Since Chomsky (1981: 252) excludes prepositions from the category of proper governors, he, along the lines of Hornstein and Weinberg 1981, relies on the rule of reanalysis, which states that "in the domain of VP, a $\mathrm{V}$ and any set of contiguous elements to its right can form a complex V" (Hornstein and Weinberg (1981: 60), cf. also Kayne 1981). Hence in 35a$\mathrm{d}$, for example, give the present to, put her engagement ring on, talk to Jack about, and live in are all reanalyzed as complex verbs, which in turn properly govern the empty categories in $35 \mathrm{a}-\mathrm{d}$, respectively. ${ }^{13}$ However, if this line of argument should be extended to 33 and 34, these two cases would incorrectly be ruled "in", because all the relevant elements in 33 and 34 are in the domain of VP and therefore complex verbs are created, by which the empty categories are properly governed. ${ }^{14,15}$ Therefore we are led to conclude that the framework proposed in Chomsky 1981 fails to provide a consistent explanation for the phenomena of preposition stranding.

Let us consider next whether the framework proposed in Chomsky $1986 \mathrm{~b}$ can cope with the facts about preposition stranding observed above. Before looking at the phenomena of prepositions stranded within VPs, it may be profitable to review briefly how Chomsky accounts for the following contrast, where prepositions are stranded within NPs.

(38) a. Which city did you witness [NP the [destruction [PP of $t]]]$ ?

${ }^{13}$ Reanalysis, however, has a number of drawbacks. For example, it seems totally counterintuitive to claim that a phrase like give the present to or put her engagement ring on should be considered as a single verb. In fact, the following contrast of the gapping construction shows that these phrases cannot be regarded as single verbs.

(i ) John [ $\mathrm{v}$ likes] apples and Nancy $\left.\mathrm{v}_{\mathrm{v}}\right]$ oranges.

(ii) *Janet [v put her engagement ring on] the desk and Sue [v ] the table. For further criticisms of reanalysis, see Inada 1981, Jones 1983, Nakajima 1984a, and Wekker and Haegeman 1985.

${ }^{14}$ Here we follow the definition of c-command proposed in Chomsky (1981: 166). Note, however, that if we follow the popular definition of c-command (i), both 33 and 34 are, again incorrectly, ruled out because reanalysis is limited to the VP (i.e. to elements that the $\mathrm{V}$ c-commands).

(i ) A c-commands B if the first branching node which dominates A dominates B.

15 To eschew this undesirable result, Chomsky might argue that the PPs in 33 are dominated by the VP node, hence complex verbs being created, while those in 34 are dominated by $\mathrm{S}$, and hence complex verbs cannot be created (see also Hornstein and Weinberg 1981). However, this structure would immediately be invalidated (see p. 60 and footnote 5) and thus cannot be taken as the correct structure for 33 and 34. 
b. ${ }^{*}$ Which city did you meet $\left[_{\mathrm{NP}}\right.$ the [man [PP from t]]]?

(Chomsky 1986b: 80)

To be more explicit, the structure for each of the NPs in 38a, b is shown below (cf. Hornstein and Lightfoot 1981, Chomsky 1981b, Radford 1981). ${ }^{16}$

(39)

a.

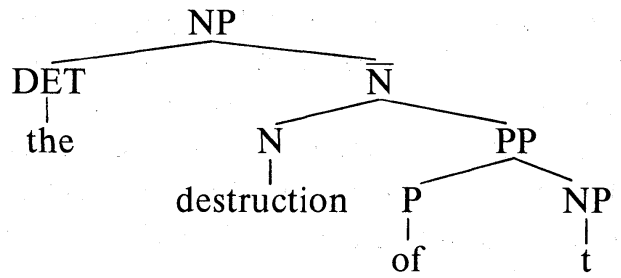

b.

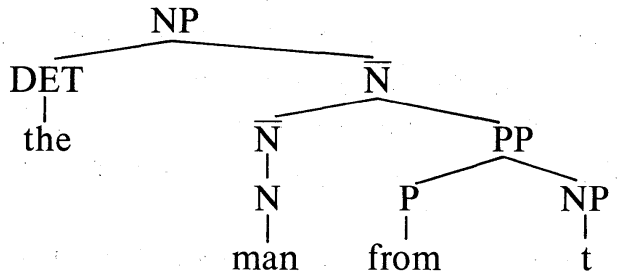

Chomsky argues that since the PP in 39a is L-marked by the $\mathrm{N}$ destruction, it is not a blocking category (BC), and hence not a barrier. Moreover, since the whole NP is also L-marked by the $\mathrm{V}$ witness, this is not a barrier, either. Therefore the extraction from the PP does not violate the Subjacency condition. On the other hand, the PP in $39 \mathrm{~b}$ is not L-marked because the sister to the $\mathrm{PP}$ is not the lexical category $\mathrm{N}$ but its projection $\overline{\mathrm{N}}$. Hence the PP does act as a barrier. Since the NP inherits barrierhood, two barriers are crossed and a Subjacency violation results. ${ }^{17}$ $38 \mathrm{~b}$.

${ }^{16}$ Chomsky suggests as another possibility the following structure for the NP in

(i )

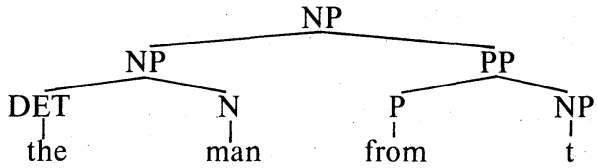

Since the discussion below in the text makes no difference whichever structure we would take, we will not go into the problem of which structure is correct.

17 Chomsky (1986b: 80) does not assume here an adjunction to PP. However, he (1986b: 65-6) does assume a PP-adjunction so that he can account for a parasitic gap construction such as (i).

(i ) What did you file $t$ [pp before [O [you read e]]]?

The PP-adjunction yields the following structure (ii) for (i), and here $\mathrm{O}$ is indeed 0 subjacent to $t$, observing the condition (iii).

(ii) What did you file $\mathrm{t}{ }_{[\mathrm{PP}} \mathrm{O}\left[{ }_{\mathrm{PP}}\right.$ before $\left[\mathrm{e}^{\prime}\right.$ [you read e]]]]? 
Now turning to the preposition stranding observed in VPs above, let us consider the following structure, which will be derived as a logical consequence of the two-level X-bar theory (cf. Emonds (1985: 27-8), Chomsky 1986b).

(40)

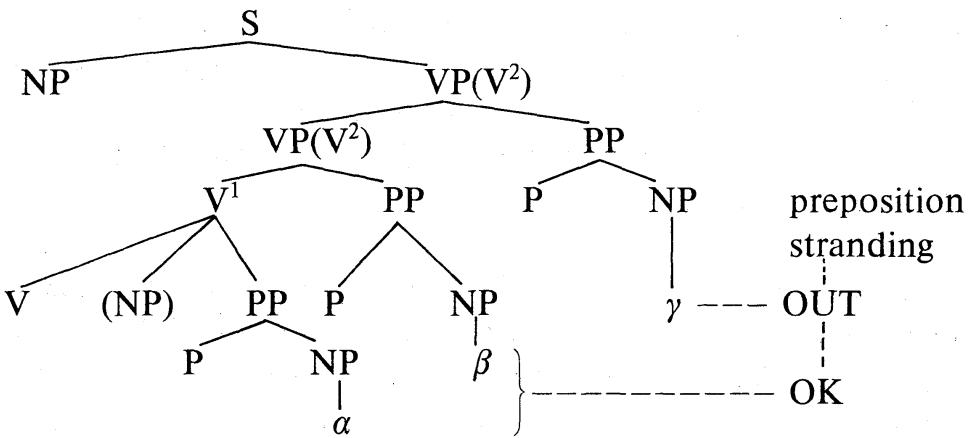

$\alpha$ moves successive-cyclically, first to the lower VP (VP-adjunction), then to the higher VP, and then to the specifier of $\mathrm{CP}(\overline{\mathrm{S}})$. Nothing bars this process, because (i) the PP under $\mathrm{V}^{1}$ is L-marked by the lexical category $\mathrm{V}$ and hence is neither a $\mathrm{BC}$ nor a barrier, (ii) the intervening $\mathrm{V}^{1}$, not being a maximal projection, is not a barrier, and (iii) each maximal projection VP is not a barrier, either, the definition of government being given in terms of exclusion, rather than in terms of inclusion (domination). Therefore the framework proposed in Chomsky 1986b can correctly handle the case of $\alpha$. Then, how about the cases of $\beta$ and $\gamma$ ? In these cases each PP does act as a barrier, since it is not L-marked. However, the intervening VPs would not be barriers if we follow the definition of government in terms of exclusion. ${ }^{18}$ Thus the cases of the extractions of $\beta$ and $\gamma$ are both only

(iii) In chain composition as in the following, forming $\left(\mathscr{C}, \mathscr{C}^{\prime}\right)$, the head of $\mathscr{C}^{\prime}$ must be 0 -subjacent to the final element of $\mathscr{C}$.

If $\mathscr{C}=\left(\alpha_{1}, \ldots, \alpha_{\mathrm{n}}\right)$ is the chain of the real gap and $\mathscr{C}^{\prime}=\left(\beta_{1}, \ldots, \beta_{\mathrm{m}}\right)$ is the chain of the parasitic gap, then the "composed chain"

$\left(\mathscr{C}, \mathscr{C}^{\prime}\right)=\left(\alpha_{1}, \ldots, \alpha_{\mathrm{n}}, \beta_{1}, \ldots, \beta_{\mathrm{m}}\right)$

is the chain associated with the parasitic gap construction and yields its interpretation. (Chomsky 1986b: 56, 65)

Notice, however, that if we apply a PP-adjunction to $38 \mathrm{~b}$, the sentence will be incorrectly ruled "in". Therefore it does not seem clear at the present stage when or on what occasions PP-adjunction should (not) be applied.

${ }^{18}$ There may be another possibility: namely that the intervening VPs inherit barrierhood from the PPs. If so, a Subjacency violation results in each of these cases. Whichever option we may take, it should be obvious that the framework proposed in Chomsky 1986 b cannot distinguish between these two cases. 
1-subjacent, observing the Subjacency condition, and we must conclude here again that Chomsky 1986b cannot distinguish between the case of the acceptable $\beta$ extraction and that of the unacceptable $\gamma$ extraction.

Now, to summarize this section, the arguments presented in 2.1. and 2.2. would support a structure like 12 or 13 , in which central and peripheral adjuncts are dominated by distinct nodes. From the discussions given in 2.3.-2.5., however, it seems legitimate that the lexical category V projects up to a triple-bar level as in 12 , not allowing free recursion at the double-bar level as in 13.

3. Concluding Remarks. In this paper we have presented several pieces of evidence on the basis of central and peripheral adjuncts, and argued that VP must have three distinct levels in terms of X-bar theory. Note, however, that this does not necessarily intend to suggest that free recursion at a certain level should not be allowed. For instance, sentence 41, in which the four adjuncts normally appear in the order given, though stylistically objectionable, is considered to have the structure 42.

(41) John hit the burglar on the head with a bat in the office at midnight.

(42) John $\left[\mathrm{v}^{3}\left[\mathrm{v}^{3}\left[\mathrm{v}^{2}\left[\mathrm{v}^{2}\left[\mathrm{~V}^{1}\right.\right.\right.\right.\right.$ hit the burglar] on the head] with a bat] in the office] at midnight].

Looking back upon the history of X-bar theory so far, we notice the gradual shift from multiplication (expansion) of projection types to minimalization (retrenchment) of them, such as typified by "the single projection type hypothesis" in Stuurman 1985 (see also Fukui 1986). This transition seems to be highly desirable from the viewpoints of language acquisition and explanatory adequacy, if, and only if, it can correctly capture a wide range of empirical evidence. The proposal in this paper may run counter to this recent trend, but it is clear that a genuinely explanatory theory of grammar is best constructed not by proceeding in defiance of empirical evidence (as provided in this paper) but by searching for a more comprehensive theory that is sensitive to a large number of linguistic phenomena.

We would like to conclude this paper by pointing out two remaining problems. The $\mathrm{V}^{3}$ system presented in this paper somewhat resembles the $\mathrm{V}^{3}$ system relating to auxiliary elements as proposed in Akmajian, Steele and Wasow 1979. It is thus to be examined in the future how our analysis is interrelated with theirs. 
Almost every work on X-bar theory explicitly or implicitly has assumed "the uniform bar-level hypothesis" across categories since it was first proposed in Chomsky 1970, but here we have confined ourselves only to the internal structure of VP. It is therefore to be also investigated whether or not this $\mathrm{V}^{3}$ system can be applied to other lexical categories.

\section{REFERENCES}

Akmajian, Adrian, Susan M. Steele, and Thomas Wasow. 1979. The category AUX in universal grammar. LI 10.1-64.

BAKER, LEROY. 1978. Introduction to generative-transformational grammar. Englewood Cliffs, N.J.: Prentice Hall.

Сномsкy, Noam. 1970. Remarks on nominalization. Readings in English transformational grammar, ed. by Roderick Jacobs and Peter Rosenbaum, 184-221. Waltham: Ginn and Company.

1981a. Lectures on government and binding. Dordrecht: Foris.

1981b. Principles and parameters in syntactic theory. Explanation in linguistics: the logical problem of language acquisition, ed. by Norbert Hornstein and David Lightfoot, 32-75. London: Longman.

1982. Some concepts and consequences of the theory of government and binding. Cambridge, MA: MIT Press.

1986a. Knowledge of language: its nature, origin, and use. New York: Praeger.

1986b. Barriers. Cambridge, MA: MIT Press.

Close, R. A. 1975. A reference grammar for students of English. London: Longman.

Dresher, Bezalel. 1974. The position and movement of prepositional phrases. Unpublished manuscript, University of Massachusetts.

EMONDS, JosEPH. 1985. A unified theory of syntactic categories. Dordrecht: Foris. FUKUI, NAOKI. 1986. A theory of category projection and its applications. Cambridge, MA: MIT dissertation.

Greenbaum, Sidney. 1969. Studies in English adverbial usage. London: Longman.

Hasegawa, Kinsuke. 1986. Kyoukai riron to shite no Barriers hihan. Gengo 15: 12.84-94.

Horn, George. 1974. The noun phrase constratint. Amherst: University of Massachusetts dissertation.

Hornstein, Norbert, and David Lightfoot. 1981. Explanation in linguistics: the logical problem of language acquisition. London: Longman.

_ _ and Amy Weinberg. 1981. Case theory and preposition stranding. LI 12.5591.

Inada, Toshiaki. 1981. Problems of reanalysis and preposition stranding. Studies in English Linguistics 9.120-31. 
JACKENDOFF, RAY. 1977. $\overline{\mathrm{X}}$ syntax: a study of phrase structure. Cambridge, MA: MIT Press.

Jones, Michael. 1983. Getting 'tough' with wh-movement. JL 19.129-59.

KAYNE, Richard. 1981. ECP extensions. LI 12.93-133.

Kuno, Susumu. 1975. Conditions for verb phrase deletion. FL 13.161-75.

LARSON, RichaRD. 1985. Bare-NP adverbs. LI 16.595-621.

Nakajima, Heizo. 1982. The $\mathrm{V}^{4}$ system and bounding category. LA 9.341-78. . 1984a. Eigo no ido gensho kenkyu. Tokyo: Kenkyusha.

1984b. Ku-hanchu no genmitsu genri. Eibungaku kenkyu 61.71-84.

Quirk, Randolph, Sidney Greenbaum, Geoffrey Leech, and Jan Svartvik. 1972.

A grammar of contemporary English. London: Longman.

1985. A comprehensive grammar of the English language. London: Longman.

RADFORD, ANDREw. 1981. Transformational syntax: a student's guide to Chomsky's extended standard theory. London: Cambridge Univ. Press.

ReINHART, TANYA. 1976. The syntactic domain of anaphora. Cambridge, MA: MIT dissertation.

1981. Definite NP anaphora and c-command domains. LI 12.605-35.

1983. Anaphora and semantic interpretation. London: Croom Helm.

RiemsDiJK, HenK VAN, and EDwin WiLliams. 1986. Introduction to the theory of grammar. Cambridge, MA: MIT Press.

Rochemont, Michael. 1986. Focus in generative grammar. Amsterdam: John Benjamins.

Ross, John Robert. 1973. Nearer to vee. Unpublished manuscript, MIT.

StuUrman, Frits. 1985. Phrase structure theory in generative grammar. Dordrecht: Foris.

Wekker, Herman, and Liliane Haegeman. 1985. A modern course in English syntax: London: Croom Helm. 